\title{
ANÁLISE FITOQUÍMICA E DETERMINAÇÃO DA CAPACIDADE ANTIOXIDANTE EM EXTRATOS DE Aniba canelilla (H.B.K.) MEZ
}

\author{
T. J. B. MESQUITA ${ }^{1}$; G. F. da SILVA ${ }^{1}$; P. M. ALBUQUERQUE ${ }^{1}$ e S. DUVOISIN JR ${ }^{1}$ \\ ${ }^{1}$ Universidade do Estado do Amazonas, Escola Superior de Tecnologia, Curso de Engenharia \\ Química, Laboratório de Química Aplicada à Tecnologia. \\ E-mail para contato: thiago.mesquita.wm@gmail.com
}

\begin{abstract}
RESUMO - A preciosa (Aniba canelilla) é uma espécie produtora de óleo essencial aromático e possível fonte de metabólitos secundários antioxidantes, compostos de grande interesse para a indústria de cosméticos. Tais metabólitos podem ser usados na produção de matérias primas ou em formulações que contenham elementos fitoquímicos benéficos para a saúde. Neste estudo foi realizada uma triagem fitoquímica para conhecer os constituintes da preciosa e avaliar seu potencial como fonte de novos antioxidantes. Os testes fitoquímicos qualitativos foram positivos para fenóis, taninos, flavonóides e saponinas. A atividade antioxidante, avaliada pelo métdo do DPPH, foi mais expressiva no extrato etanólico de folhas, seguida do extrato proveniente dos galhos. Observou-se uma queda significativa da atividade antioxidante nos extratos obtidos após a extração de óleo essencial. Verifica-se que $A$. canelilla apresenta metabólitos capazes de inibir os processos de oxidação, através do sequestro de radicais livres, apresentando potencial como fonte de antioxidantes.
\end{abstract}

\section{INTRODUÇÃO}

A oxidação ocorre no corpo humano como consequência da combustão biológica, que está envolvida no processo de respiração. A oxidação incompleta provoca a produção de espécies reativas de oxigênio (EROs) ou radicais livres (RL), danosos ao organismo, gerando o estresse oxidativo, responsável pelo envelhecimento e até o surgimento de câncer (Dröge, 2002; Valko et al., 2007). A quantidade de RL nos seres vivos é controlada por antioxidantes, que podem ser produzidos pelo próprio ser vivo ou adquiridos pela dieta, podendo ser ingeridos compostos sintéticos ou naturais. Atualmente, a busca por antioxidantes naturais tem aumentado, pois além de serem mais facilmente aceitos na sociedade, sua capacidade de inibir a formação ou a propagação de RL apresenta pouco efeito colateral quando comparados aos seus equivalentes sintéticos (De La Roche et al., 2010; Russo et al., 2012).

A espécie Aniba canelilla (H.B.K.) Mez é nativa da região Amazônica, popularmente conhecida como preciosa (Maia et al., 2000). Esta árvore fornece madeira de ótima qualidade, apropriada para mobiliário e construção civil (Lupe, 2007) e é enormemente utilizado na medicina popular contra artritismo, esgotamento nervoso, e também como redutora da albumina no sangue (Silva, 1977). Os óleos essenciais das folhas e galhos finos possuem como composto majoritário o 1-nitro-2-feniletano, uma molécula rara em produtos naturais, derivada da fenilalanina (Lupe, 2007). Com relação aos extratos dessa espécie, Silva et al. 
(2007) reportaram a presença de benzaldeído, $(E)$ - $\beta$-ocimeno, mirceno, trans- $p$-menth-2-en-1ol, safrol, eugenol, metileugenol, selil-11-en-4- $\alpha$-ol, além do 1-nitro-2-feniletano (composto majoritário) em extratos metanólicos obtidos de troncos de $A$. canelilla.

Um grande número de plantas aromáticas contém compostos que exibem propriedades antioxidantes, e estes efeitos devem-se principalmente aos compostos fenólicos, tais como flavonóides, ácidos fenólicos e diterpenos fenólicos (Miliauskas et al., 2004). Portanto, a espécie $A$. canelilla apresenta potencial como fonte de novos compostos antioxidantes.

Com o intuito de avaliar e estimar a capacidade antioxidante dos compostos de origem vegetal, os mais diversos métodos de análise vêm sendo utilizados, os quais se relacionam com a geração de radicais e que agem por diferentes mecanismos, como por exemplo, o FRAP (Ferric Reducing/Antioxidant Power), que consiste na redução do ferro férrico em um $\mathrm{pH}$ baixo, e os ensaios com ABTS (2,2-azino-bis(ethylbenzo-thiazoline-6-sulfonic acid) diammonium salt), nos quais são gerados cromóforos azuis ou verdes pela reação do ABTS com persulfato de potássio, e cujos resultados são expressos por meio de concentrações equivalentes (Re et al., 1999; Zhou et al., 2004; Dudonné et al., 2009). Contudo, expressar os resultados com base na equivalência molar envolve o uso de modelagens matemáticas, que podem dificultar a compreensão e interpretação dos valores obtidos. Dessa forma, seria de grande utilidade para fins comparativos se a capacidade antioxidante fosse expressa por meio de métodos confiáveis e simples, além de serem expostos em termos mais comuns.

Sendo assim, neste estudo foi investigada a atividade antioxidante de extratos de $A$. canelilla, os quais foram submetidos a uma triagem fitoquímica. Para determinar a atividade antioxidante foi desenvolvido um método para a exposição dos resultados obtidos pela redução do radical 2,2-difenil-1-picril-hidrazila (DPPH) pelos extratos, em relação ao padrão ácido ascórbico, a fim de facilitar a avaliação da capacidade antioxidante da espécie.

\section{MATERIAIS E MÉTODOS}

\subsection{Material Vegetal}

Folhas e galhos finos foram coletados da base da copa de árvores de $A$. canelilla. A coleta foi realizada no período chuvoso na Reserva Florestal Adolpho Ducke do Instituto Nacional de Pesquisas da Amazônia, localizada no Km 26 da Rodovia AM-010, em ManausAM. Após a coleta, o material vegetal foi seco em temperatura ambiente por 10 dias e moído em moinho de facas com tela de $3 \mathrm{~mm}$. Foi obtido o óleo essencial por arraste a vapor em aparelho tipo Clevenger, onde $100 \mathrm{~g}$ de material vegetal foram destilados com $1000 \mathrm{~g}$ de água destilada a $100^{\circ} \mathrm{C}$ durante $3 \mathrm{~h}$ e 30 min para folhas e $6 \mathrm{~h}$ para galhos (Chaar, 2000).

\subsection{Preparo dos Extratos Etanólicos}

As folhas e galhos secos e triturados, assim como os resíduos obtidos da hidrodestilação, foram macerados com álcool etílico de cereais à temperatura ambiente por 3 ciclos de $72 \mathrm{~h}$. Os extratos obtidos foram filtrados e o solvente evaporado. Os extratos brutos resultantes foram ressuspendidos em etanol-água (1:3) e submetidos à partição líquidolíquido, utilizando $n$-hexano e diclorometano. As frações solúveis em $n$-hexano e em diclorometano foram rotaevaporadoas a $40^{\circ} \mathrm{C}$ para a retirada do solvente (Silva, 2012). 


\subsection{Prospecção Preliminar de Constituintes em Aniba canelilla}

A fim de realizar uma triagem fitoquímica preliminar em extratos de folhas e galhos de A. canelilla foi empregada a metodologia descrita por Matos (2009). Foi avaliada a presença de esteróides e triterpenóides, flavonóides, taninos e fenóis, saponinas e alcalóides.

\subsection{Estudo da Capacidade Antioxidante}

A partir de uma solução estoque dos extratos secos $\left(1,280 \mathrm{mg} \cdot \mathrm{mL}^{-1}\right)$ foram feitas diluições sucessivas em metanol P.A., até a concentração de $5,0 \mu \mathrm{g} \cdot \mathrm{mL}^{-1}$. A curva analítica foi preparada com ácido ascórbico. Foram transferidos $50 \mu \mathrm{L}$ de cada concentração das amostras, em triplicata, para tubos de ensaio, sendo adicionados $1.950 \mu \mathrm{L}$ da solução de DPPH• $0,06 \mathrm{M}$ seguido de homogeneização da mistura. Após 30 min de reação foi medida a absorbância em espectrofotômetro a $517 \mathrm{~nm}$ (Silva, 2012).

A capacidade antioxidante foi analisada relacionando os coeficientes angulares das equações obtidas para as amostras com o coeficiente angular da curva padrão de ácido ascórbico, a partir da construção do gráfico da absorbância a $517 \mathrm{~nm}$ versus a concentração. Dessa forma, foram utilizados os dados obtidos diretamente do espectrofotômetro, relacionando o comportamento dos pontos obtidos para uma amostra com o comportamento da substância padrão. Portanto, a capacidade antioxidante foi determinada pela relação:

Onde:

$$
\text { C. } A .=\left(\frac{m}{\alpha}\right) * 100
$$

C. A. = capacidade antioxidante;

$\mathrm{m}=$ coeficiente angular obtido para a amostra;

$\alpha=$ coeficiente angular da curva padrão.

\section{RESULTADOS E DISCUSSÃO}

\subsection{Triagem Fitoquímica}

A triagem fitoquímica preliminar dos extratos etanólicos de folhas e galhos de $A$. canelilla revelou a presença de fenóis, taninos, além de flavonóides e saponinas (Tabela 1). Cada teste da triagem foi realizado em triplicata.

Tabela 1 - Análise fitoquímica preliminar dos extratos etanólicos de A. canelilla.

\begin{tabular}{ccc}
\hline \multirow{2}{*}{ Classe de metabólitos } & \multicolumn{2}{c}{ Resultados } \\
& Extrato de Galhos & Extrato de Folhas \\
\hline Fenóis & + & + \\
Taninos & + & + \\
Flavonóides & + & + \\
Alcalóides & - & - \\
Esteróides & - & - \\
Saponinas & + & + \\
\hline
\end{tabular}

+ Presença; - Ausência 
O teste realizado para fenóis e taninos forneceu uma coloração escura e azulada. Esses compostos formam complexos coloridos com o íon $\mathrm{Fe}^{+3}$, devido à redução causada pelo magnésio na presença do ácido, que altera a coloração do composto flavonóidico. Dessa forma, o teste é positivo para flavonóides que contenham o núcleo benzopirona na sua estrutura química (Martínez, 2005).

Para o teste com NaOH, o extrato etanólico dos galhos apresentou uma coloração vermelha alaranjada, indicativo da presença de flavonóis e para o proveniente das folhas observou-se uma coloração amarelada, indicativo da presença de flavonas, flavonóis e xantonas. As reações com $\mathrm{NaOH}$ são utilizadas para identificação de fenóis na triagem de grupos funcionais, e sendo os flavonóides polifenóis, estas reações podem ser utilizadas. $\mathrm{O}$ mecanismo consiste na formação de fenóxidos (Sofiatti, 2009).

Não foi detectada a presença de alcalóides nem de esteróides e triterpenos nos extratos de folhas e galhos de $A$. canelilla. Para saponinas, ambos os extratos apresentaram formação de espumas, sendo que para o extrato das folhas observou-se formação de espuma mais intensa do que para o de galhos.

A presença de flavonóides nos extratos pode fornecer uma capacidade antioxidante efetiva devido à sinergia que é criada entre as moléculas (Castillo et al., 2000). Em muitos casos, ao se realizar a análise antioxidante e se analisar o número de fenóis totais, é possível encontrar correlações diretas entre a concentração da amostra e o sequestro de radicais. Contudo, estes resultados dependem da natureza da amostra, do teste e da interação desses compostos que detêm a atividade com os outros presentes (Payet et al., 2005). Taninos são polifenóis presentes em muitos alimentos. Eles têm sido reconhecidos como antioxidantes e por possuírem ação protetora contra danos ao DNA (Banerjee et al., 2005).

\subsection{Atividade Antioxidante}

A atividade antioxidante de extratos de folhas e galhos de $A$. canelilla foi comparada com a do ácido ascórbico, que possui alta capacidade antioxidante (Mensor et al., 2001). Os testes foram realizados em triplicata e os resultados foram expressos como média de cada triplicata. A Figura 1 representa o gráfico de regressão linear dos pontos obtidos pela leitura em espectrofotômetro da diminuição da absorbância a $517 \mathrm{~nm}$.

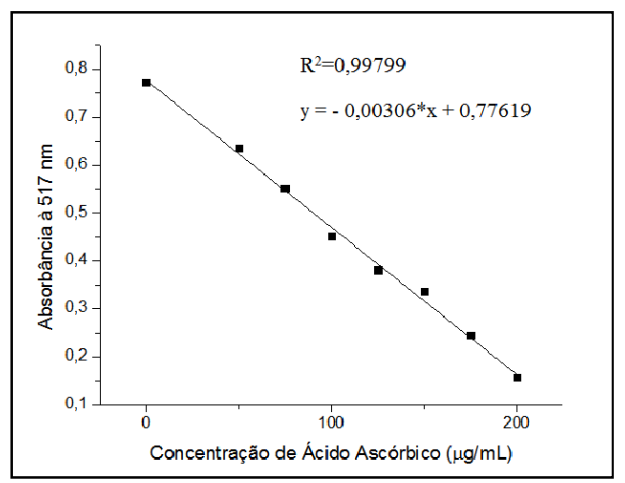

Figura 1 - Curva analítica do ácido ascórbico frente ao radical livre DPPH. 
A capacidade antioxidante dos extratos e frações, comparada à do ácido ascórbico pode ser visualizada nas Figuras 2 e 3.
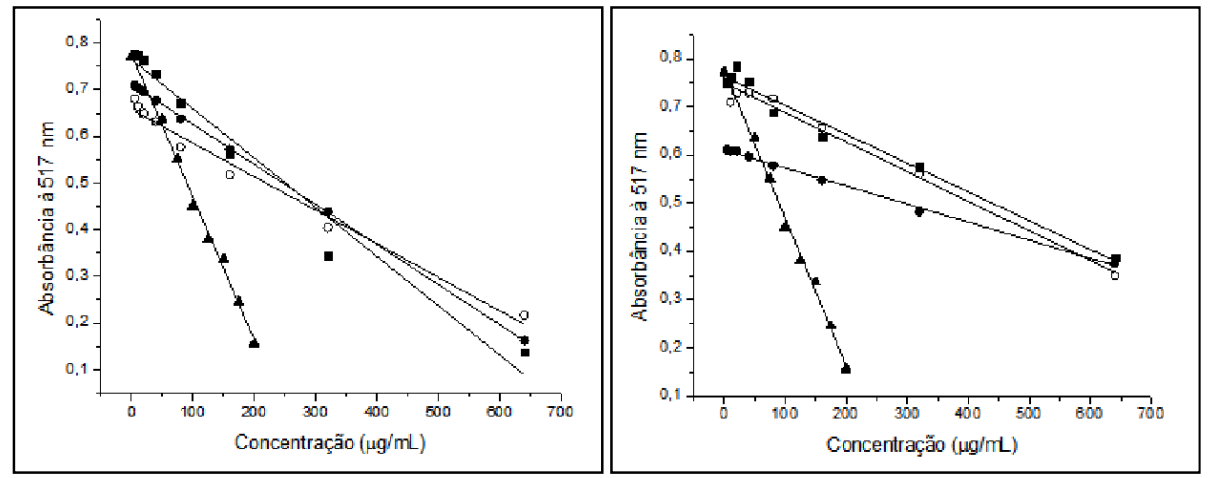

Figura 2 - Capacidade antioxidante do ácido ascórbico ( $\mathbf{\Lambda})$. Em (A): extrato bruto etanólico $(\boldsymbol{\square})$, fase diclorometânica $(\bullet)$ e fase hexânica $(\circ)$ de folhas de $A$. canelilla. Em (B): extrato bruto etanólico $(\boldsymbol{\square})$, fase diclorometânica $(\bullet)$ e fase hexânica $(\circ)$ de galhos de $A$. canelilla.

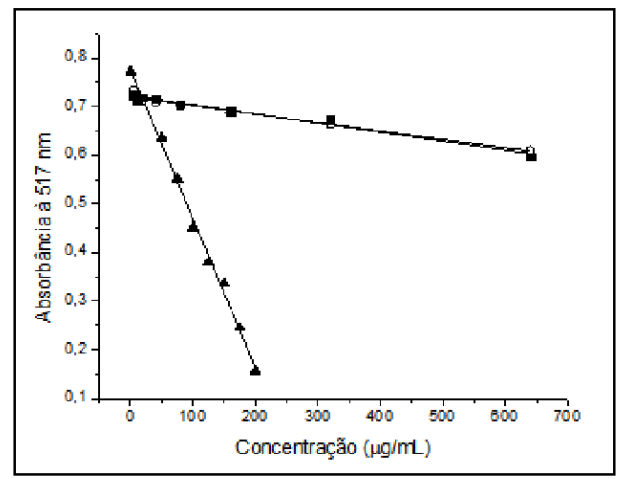

Figura 3 - Capacidade antioxidante do ácido ascórbico ( $\boldsymbol{\Lambda})$ e extrato bruto etanólico do resíduo obtido da hidrodestilação das folhas $(\bullet)$ e dos galhos de $A$. canelilla

A partir da relação entre os coeficientes angulares das retas obtidas para o padrão ácido ascórbico e para os extratos e frações, foi calculada a capacidade antioxidante (Tabela 2).

Tabela 2 - Capacidade antioxidante (\%) dos extratos e frações de folhas e galhos e dos resíduos da hidrodestilação de folhas e galhos de $A$. canelilla.

\begin{tabular}{lcccc}
\hline \multicolumn{1}{c}{ Amostras } & $\begin{array}{c}\text { Galho } \\
\mathbf{( \% )}\end{array}$ & $\begin{array}{c}\text { Resíduo Galho } \\
(\mathbf{\%})\end{array}$ & $\begin{array}{c}\text { Folha } \\
\mathbf{( \% )}\end{array}$ & $\begin{array}{c}\text { Resíduo Folha } \\
(\mathbf{\%})\end{array}$ \\
\hline Extrato Etanólico Bruto & 19,53 & 18,10 & 34,97 & 6,08 \\
Fase Hexânica & 20,37 & 11,72 & 23,49 & 5,64 \\
Fase Diclorometânica & 12,25 & 11,29 & 28,06 & -- \\
\hline
\end{tabular}

Segundo Okonogi et al. (2007), a atividade antioxidante das plantas é atribuída principalmente pelos compostos ativos presentes nelas e a quantidade desses compostos em cada parte da planta é usualmente diferente. Verifica-se que na Tabela 2 que a atividade antioxidante foi mais expressiva no extrato e frações provenientes de folhas, seguidos das 
frações provenientes dos galhos. Dessa forma, é possível afirmar que as substâncias responsáveis pela atividade antioxidante são produzidas em maior quantidade nas folhas do que nos galhos. Ao se analisar o estudo fitoquímico preliminar nota-se que os resultados foram também mais expressivos para os extratos de folha, como no caso de formação de espuma indicativa da presença de saponinas e escurecimento da solução no teste para taninos.

A diferença que pode existir entre os teores de metabólitos secundários nos galhos e folhas pode ser explicada pelo fato de que algumas substâncias não são necessárias para toda a planta, e o metabolismo secundário origina compostos que não possuem uma distribuição universal, sendo inclusive possível o uso desses compostos em estudos taxonômicos (Bennett e Wallsgrove, 1994).

Observou-se uma queda significativa na capacidade antioxidante quando se compara o extrato bruto e as frações de folhas com o extrato e frações do resíduo obtido das folhas. Este resultado pode ser explicado se levarmos em consideração que, ao se extrair o óleo essencial, os compostos responsáveis pelo sequestro de radicais livres também podem ter sido retirados, ou ainda, que estes compostos tenham se degradado durante a hidrodestilação.

Os extratos etanólicos brutos apresentaram, com exceção dos extratos de galhos, as maiores atividades antioxidantes. Existe uma maior solubilidade das substâncias antioxidantes em solventes polares, pois o ensaio utilizando o DPPH quantifica a capacidade das substâncias em doar hidrogênio radicalar a este radical, e assim, quanto maior o número de hidroxilas presentes na amostra, maior será o potencial antioxidante e consequentemente sua polaridade (Duarte-Almeida et al., 2006), contudo no caso dos galhos pode ser inferido também que existem componentes antioxidantes de característica apolar resultando em uma capacidade de redução semelhante à fração etanólica.

No trabalho realizado por Silva (2012), a capacidade antioxidante foi obtida por meio da concentração eficiente a $50 \%\left(\mathrm{CE}_{50}\right)$, ou seja, a concentração em que $50 \%$ dos radicais livres são sequestrados. Para o ácido ascórbico, o valor encontrado de $\mathrm{CE}_{50}$ foi de 113,55 $\mu \mathrm{g} \cdot \mathrm{mL}^{-1}$. Para o extrato etanólico de galhos, a $\mathrm{CE}_{50}$ foi de $449,4 \mu \mathrm{g} \cdot \mathrm{mL}^{-1}$ e para o de folhas, $331,2 \mu \mathrm{g} \cdot \mathrm{mL}^{-1}$. Para os resíduos de galhos, a $\mathrm{CE}_{50}$ foi de $643 \mu \mathrm{g} \cdot \mathrm{mL}^{-1}$ e para os de folhas, $1316,9 \mu \mathrm{g} \cdot \mathrm{mL}^{-1}$. Quando comparado com os dados de atividade antioxidante obtidos neste trabalho, podem ser observadas semelhanças, indicando a viabilidade do método, haja vista a simplicidade da análise. O método tem por vantagem a utilização de dados obtidos diretamente do espectrofotômetro, garantindo uma confiabilidade maior aos resultados. A presença de compostos com atividade antioxidante pode influenciar no valor do coeficiente angular das curvas, pois uma maior quantidade desses compostos fornecerá um valor de coeficiente angular mais próximo ao do padrão utilizado.

Em estudo realizado por Fogaça et al. (2013) foi utilizada uma metodologia semelhante para o estudo da atividade antioxidante de Terminalia catappa Linn. Foram construídos gráficos de absorbância versus o tempo e fez-se uma regressão linear dos pontos, sendo o coeficiente angular tido como fator antioxidante, permitindo o estudo dos vários estágios de maturação da espécie, e também o conteúdo de compostos fenólicos da planta. 


\section{CONCLUSÃO}

O extrato de A. canelilla apresenta biomoléculas capazes de inibir os processos de oxidação, através do sequestro de radicais livres. Com a metodologia utilizada neste estudo pode-se obter respostas mais precisas em ambientes sob mais controle, para formulação de padrões analíticos para o estudo do potencial antioxidante, análises cruzadas entre fatores e interações dos compostos que forneçam uma compreensão maior da capacidade biológica da espécie, de forma mais simples.

\section{AGRADECIMENTOS}

Os autores agradecem à FAPEAM, CNPq e CAPES pelo suporte financeiro, ao INPA e à UEA pela infraestrutura concedida para a realização deste trabalho.

\section{REFERÊNCIAS}

BANERJEE, A.; DASGUPTA, N.; DE, B. In vitro study of antioxidant activity of Syzygium cumini fruit. Food Chem., v. 90,p. 727-733, 2005.

BENNETT, R. N.; WALlSGROVE, R. M. Secondary metabolites in plant defence mechanisms. New Phytologist, v. 127, p. 617-633, 1994.

CASTILlO, J.; BENAVENTE-GARCÍA, O.; LORENTE, J.; ORTUÑO, A; DEL RIO, J. A. Antioxidant activity of phenolics extracted from Olea europaea L. leaves, Food Chem., v. 68, p. 457- 462, 2000.

CHAAR, J. S. Estudos analíticos e modificação química por acetilação do linalol contido no óleo essencial da espécie Aniba dukei Kostermans. Tese (Doutorado em Química). Instituto de Química de São Carlos. Universidade de São Paulo. São Carlos, 2000.

DE LA ROCHE, M.; SEAGROVE, S.; MEHTA, A. ; DIVEKAR, P.; CAMPBELL, S.; CURNOW, A. Using natural dietary sources of antioxidants to protect against ultraviolet and visible radiation-induced DNA damage: An investigation of human green tea ingestion. $J$. Photoch. Photobio. B, v. 101, p. 169-173, 2010.

DUARTE-ALMEIDA, J. M.; DOS SANTOS, R. J.; GENOVESE, M. I.; LAJOLO, F. M. Avaliação da atividade antioxidante. Ciênc. Tecnol. Aliment., v. 26, p. 446-452, 2006.

DUDONNÉ, S.; VITRAC, X.; COUTIÈRE, P.; WOILlEZ, M.; MÉRILlON, J.; Comparative study of antioxidant properties and total phenolic content of 30 plant extracts of industrial interest using DPPH, ABTS, FRAP, SOD and ORAC assays.; J. Agr. Food Chem., v. 571, p. 768-1774, 2009.

DRÖGE, W; Free Radicals in the physiological control of cell function. Physiol. Rev., v. 82, p. 47-95, 2002.

FOGAÇA, D. N. L.; JÚNIOR, W. R.S P.; JÚNIOR, N. O. R.; NUNES, G. S. Atividade antioxidante e teor de fenólicos de folhas da Terminalia catappa Linn em diferentes estágios de maturação. Rev Ciênc Farm Básica Apl., v. 34, p. 257-261, 2013. 
LUPE, F. A. Estudo da composição química de óleos essenciais de plantas aromáticas da Amazônia. 2007. 102p. Dissertação (Mestrado em Química), Instituto de Química, Universidade Estadual de Campinas, Campinas, 2007.

MAIA, J. G. S.; ZOHBI, M. G. B.; ANDRADE, E. H. A. Plantas aromáticas na Amazônia e seus óleos essenciais. Belém: Museu Paraense Emílio Goeldi, 2000.

MARTÍNEZ, A. Flavonóides. Facultad de Química Farmacéutica, Universidad de Antioquia. 2005.

MATOS, F. J. A. Introdução à fitoquímica experimental. Fortaleza: Edições UFC, 2009.

MENSOR, L. L.; MENEZES, F. S.; LEITÃO, G. G.; REIS, A. S.; DOS SANTOS, T. C.; COUBE, C. S.; LEITÃO, S. G. Screening of Brazilian plant extracts for antioxidant activity by the use of DPPH free radical method. Phytother. Res., v. 15, p. 127-130, 2001.

MILIAUSKAS, G.; VAN BEEK, T. A.; VENSKUTONIS, P. R.; LINSEN, J. P. H.; WAARD, P. Antioxidative activity of Geranium macrorrhizum. Eur. Food Res. Technol., v. 218, p. 253-261, 2004.

RE, R.; PELlEGRINI, N.; PROTEGGENTE, A.; PANNALA, A.; YANG, M.; RICEEVANS, C. Antioxidant activity applying an improved ABTS radical cation decolorization assay. Free Radical Bio. Med., v. 26, p. 1231-1237, 1999.

RUSSO, M.; SPAGNUOLO, C.; TEDESCO, I.; BILOTTO, S.; RUSSO, G. L. The flavonoid quercetin in disease prevention and therapy: facts and fancies. Biochem. Pharmacol. v, 83, p. 6-15, 2012.

OKONOGI, S.; TACHAKITTIRUNGROD, S.; CHOWWANAPOONPOHN, S. Study on antioxidant activity of certain plants in Thailand: mechanism of antioxidant action of guava leaf extract. Food Chem., v. 103, p. 381-388, 2007.

PAYET, B., SING, A. S. C., SMADJA, J. Assessment of antioxidant activity of cane brown sugars by ABTS and DPPH radical scavenging assays: determination of their polyphenolic and volatile constituents. J. Agr. Food Chem., v. 53, p. 10074-10079, 2005.

SILVA, M. F. Nomes vulgares de plantas amazônicas. Manaus: INPA, 1977.

SILVA, G. F. Estudo do potencial biotecnológico de Aniba canelilla (H.B.K) Mez para formulação de cosméticos. Dissertação (Mestrado em Biotecnologia e Recursos Naturais) Escola Superior de Ciências da Saúde, Universidade do Estado do Amazonas. Manaus, 2012.

SILVA, J. K. R.; SOUSA, P. J. C.; ANDRADE, E. H. A.; MAIA, J. G. S. Antioxidant capacity and cytotoxicity of essential oil and methanol extract of Aniba canelilla (H. B. K.) Mez. J. Agr. Food Chem., v. 55, p. 9422-9426, 2007.

SOFIATTI, F. T. Estudo fitoquímico e atividades biológicas preliminares de extratos de Polygonum acre (Polygonaceae) H.B.K e Synadenium carinatum (Euphorbiaceae) Boiss. (Mestrado em Ciências Farmacêuticas). Araraquara, Universidade Estadual Paulista, 2009.

VALKO, M.; LEIBFRITZ, D.; MONCOL, J.; CRONIN, M.T.D.; MAZUR, M.; TELSER, J. Free radicals and antioxidants in normal physiological functions and human disease. Int. $J$. Biochem. Cell B., v. 39, p. 44-84, 2007.

ZHOU, K., LAUX, J. J.; YU, L. Comparison of Swiss red wheat grain and fractions for their antioxidant properties. J. Agr. Food Chem., v. 52, p. 1118-1123, 2004. 